\title{
Correction to: Documenting lemming population change in the Arctic: Can we detect trends?
}

Dorothée Ehrich $(\mathbb{0}$, Niels M. Schmidt $(\mathbb{0}$, Gilles Gauthier $(\mathbb{0}$, Ray Alisauskas, Anders Angerbjörn, Karin Clark, Frauke Ecke, Nina E. Eide, Erik Framstad, Jay Frandsen, Alastair Franke, Olivier Gilg, Marie-Andrée Giroux, Heikki Henttonen, Birger Hörnfeldt, Rolf A. Ims, Gennadiy D. Kataev, Sergey P. Kharitonov, Siw T. Killengreen, Charles J. Krebs, Richard B. Lanctot, Nicolas Lecomte, Irina E. Menyushina, Douglas W. Morris, Guy Morrisson, Lauri Oksanen, Tarja Oksanen, Johan Olofsson, Ivan G. Pokrovsky, Igor Yu. Popov, Donald Reid, James D. Roth, Sarah T. Saalfeld, Gustaf Samelius, Benoit Sittler, Sergey M. Sleptsov, Paul A. Smith, Aleksandr A. Sokolov, Natalya A. Sokolova, Mikhail Y. Soloviev, Diana V. Solovyeva

Published online: 11 October 2019

Correction to: Ambio https://doi.org/10.1007/s13280-019-01198-7

In the original published article, some of the symbols $(\boldsymbol{\Lambda}, \boldsymbol{\star}$, $\bullet, \square, \triangle, \triangle$ ) in figure 1 were modified incorrectly (\#, $\mathbb{W}, \$$, ', *,*) during the typesetting and publication process. The correct version of Fig. 1 is provided in this correction.

The original article has been corrected.

The original article can be found online at https://doi.org/10.1007/ s13280-019-01198-7. 

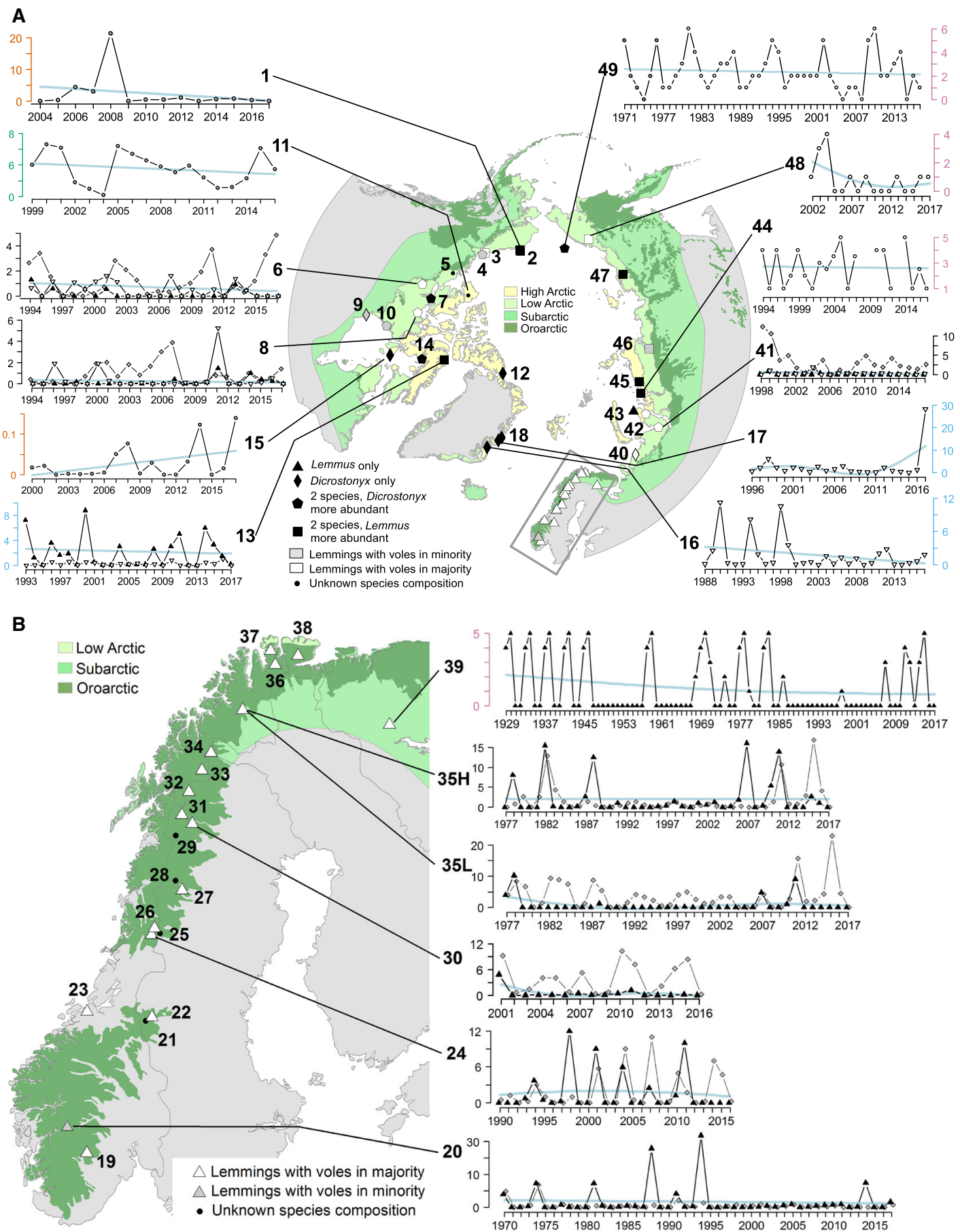

Fig. 1 Maps showing the locations of lemming monitoring sites in (A) Circumpolar region and (B) Fennoscandia (delimited by the large grey square in panel A). Different shadings of green indicate the delimitations of bioclimatic subzones. The high Arctic, low Arctic and Subarctic are drawn according to CAFF (2013) and the Oroarctic, which is customarily pooled with the arctic tundra in global biome overviews and represents potential habitat for lemmings south of the Arctic proper, according to Virtanen et al. (2016). Numbers refer to the sites as listed in Table 1 and symbols indicate small rodent community composition. Time series of annual small rodent abundance estimates are presented for selected sites (graphs for the remaining sites are given in Fig S1). On the time series graphs, triangles represent lemmings (upwards and black for Lemmus, and downwards and white for Dicrostonyx), circles represent data not identified to species such as winter nests, qualitative indices or incidental observations, whereas grey squares represent voles (all species pooled). The colour of the y-axis indicates the data type: black refers to individuals caught per 100 trap-nights $(6,8,41$ and all Fennoscandia except 39), light blue to density in individuals per ha (13, 16, 17), green to winter nest density in nests per ha (11), orange to incidental observations (numbers seen per observer-day [1], or observer-hour [15]) and purple to qualitative indices $(39,44,48,49)$. Smoothed trend lines for the total abundance of lemmings are shown in light blue. $35 \mathrm{H}$ and $35 \mathrm{~L}$ refer to the highland and lowland series of Joatka (Table S3) 
Publisher's Note Springer Nature remains neutral with regard to jurisdictional claims in published maps and institutional affiliations.

Dorothée Ehrich $(\square)$

Address: UiT The Arctic University of Norway, Framstredet 39, 9037

Troms $\emptyset$, Norway.

e-mail: dorothee.ehrich@uit.no

\section{Niels M. Schmidt}

Address: Arctic Research Centre, Department of Bioscience, Aarhus University, Frederiksborgvej 399, 4000 Roskilde, Denmark.

e-mail:nms@bios.au.dk

\section{Gilles Gauthier}

Address: Département de Biologie and Centre d'Études Nordiques, Université Laval, 1045 avenue de la Médecine, Québec, QC G1V 0A6, Canada.

e-mail: gilles.gauthier@bio.ulaval.ca

\section{Ray Alisauskas}

Address: Wildlife Research Division, Environment and Climate Change Canada, 115 Perimeter Road, Saskatoon, SK S7N 0X4, Canada.

e-mail: ray.alisauskas@ canada.ca

\section{Anders Angerbjörn}

Address: Department of Zoology, Stockholm University, 10691 Stockholm, Sweden.

e-mail: anders.angerbjorn@ zoologi.su.se

\section{Karin Clark}

Address: Environment and Natural Resources, PO Box 1320, Yellowknife, NT X1A 2L9, Canada.

e-mail: Karin_clark@gov.nt.ca

\section{Frauke Ecke}

Address: Department of Wildlife, Fish, and Environmental Studies, Swedish University of Agricultural Sciences, 90183 Umeå, Sweden. e-mail: frauke.ecke@slu.se

\section{Nina E. Eide}

Address: Norwegian Institute for Nature Research, P.O.Box 5685, Torgard, 7485 Trondheim, Norway.

e-mail: nina.eide@nina.no

\section{Erik Framstad}

Address: Norwegian Institute for Nature Research, Gaustadalleen 21, 0349 Oslo, Norway.

e-mail: erik.framstad@nina.no

\section{Jay Frandsen}

Address: Parks Canada, PO Box 1840, 81 Kingmingya, Inuvik, NT X0E0T0, Canada

e-mail: jay.frandsen@pc.gc.ca

\section{Alastair Franke}

Address: Department of Renewable Resources, University of Alberta, 751 General Services Building, Edmonton, AB T6G 2H1, Canada. e-mail: Alastair.Franke@ales.ualberta.ca

\section{Olivier Gilg}

Address: UMR 6249 Chrono-Environnement, Université de Bourgogne Franche-Comté, 16 route de Gray, 25000 Besançon, France.
Address: Groupe de recherche en Ecologie Arctique, 16 rue de Vernot, 21440 Francheville, France.

e-mail: olivier.gilg@gmail.com

Marie-Andrée Giroux

Address: K.-C.-Irving Research Chair in Environmental Sciences and Sustainable Development, Université de Moncton, 18 avenue Antonine-Maillet, Moncton, NB E1A 3E9, Canada.

e-mail: marie-andree.giroux@umoncton.ca

\section{Heikki Henttonen}

Address: Natural Resources Institute Finland, Latokartanonkaari 9, 00790 Helsinki, Finland.

e-mail: heikki.henttonen@luke.fi

\section{Birger Hörnfeldt}

Address: Department of Wildlife, Fish, and Environmental Studies, Swedish University of Agricultural Sciences, 90183 Umeå, Sweden. e-mail: birger.hornfeldt@slu.se

\section{Rolf A. Ims}

Address: UiT The Arctic University of Norway, Framstredet 39, 9037

Troms $\varnothing$, Norway.

e-mail: rolf.ims@uit.no

\section{Gennadiy D. Kataev}

Address: Laplandskii Nature Reserve, Per. Zelenyi 8, Monchegorsk, Murmansk Region, Russia.

e-mail:kataev@laplandzap.ru

\section{Sergey P. Kharitonov}

Address: Bird Ringing Centre of Russia, Moscow, Russia 117312. e-mail: serpkh@gmail.com

\section{Siw T. Killengreen}

Address: UiT The Arctic University of Norway, Framstredet 39, 9037

Troms $\varnothing$, Norway.

e-mail: siw.killengreen@uit.no

\section{Charles J. Krebs}

Address: Department of Zoology, University of British Columbia, 6270 University Blvd, Vancouver, BC V6T 1Z4, Canada.

e-mail: krebs@zoology.ubc.ca

\section{Richard B. Lanctot}

Address: Migratory Bird Management Division, U.S. Fish and Wildlife Service, 1011 East Tudor Road, MS 201, Anchorage, AK 99503, USA.

e-mail: richard_lanctot@fws.gov

\section{Nicolas Lecomte}

Address: K.-C.-Irving Research Chair in Environmental Sciences and Sustainable Development, Université de Moncton, 18 avenue Antonine-Maillet, Moncton, NB E1A 3E9, Canada.

e-mail: nicolas.lecomte@umoncton.ca

\section{Irina E. Menyushina}

Address: Moscow, Russia.

e-mail: v.n.ira@mail.ru

\section{Douglas W. Morris}

Address: Department of Biology, Lakehead University, 954 Oliver Road, Thunder Bay, ON PTB 5E1, Canada.

e-mail: douglas.morris@lakeheadu.ca 


\section{Guy Morrisson}

Address: National Wildlife Research Centre, Environment and Climate Change Canada, Carleton University, Ottawa, ON, Canada.

e-mail: guy.morrison@ec.gc.ca

\section{Lauri Oksanen}

Address: Department of Arctic and Marine Biology, UiT - The Arctic University of Norway, Postboks 1621, 9509 Alta, Norway.

Address: Department of Biology, Section of Ecology, University of Turku, 20014 Turku, Finland.

e-mail: lauoks@uit.no; lauoks@utu.fi

\section{Tarja Oksanen}

Address: Department of Arctic and Marine Biology, UiT - The Arctic University of Norway, Postboks 1621, 9509 Alta, Norway.

Address: Department of Biology, Section of Ecology, University of Turku, 20014 Turku, Finland.

e-mail: tarja.oksanen@uit.no; tamaoks@utu.fi

\section{Johan Olofsson}

Address: Department of Ecology and Environmental Science, Umeå University, 90187 Umeå, Sweden.

e-mail: johan.olofsson@umu.se

\section{Ivan G. Pokrovsky}

Address: Max-Planck Institute for Ornithology, Am Obstberg, 1, 78315 Radolfzell, Germany.

Address: Laboratory of Ornithology, Institute of Biological Problems of the North, 18 Portovaya Str, Magadan 685000, Russia.

Address: Arctic Research Station of Institute of Plant and Animal Ecology, Ural Branch, Russian Academy of Sciences, Zelenaya Gorka Str. 21, Labytnangi, Russia 629400.

e-mail: ivanpok@mail.ru

\section{Igor Yu. Popov}

Address: A.N. Severtsov Institute of Ecology and Evolution, Russian Academy of Sciences, 33 Leninskij prosp, Moscow, Russia 119071. e-mail: iyupopov@mail.ru

\section{Donald Reid}

Address: Wildlife Conservation Society Canada, 169 Titanium Way, Whitehorse, Yukon Y1A 5T2, Canada.

e-mail: dreid@wcs.org

\section{James D. Roth}

Address: Department of Biological Sciences, University of Manitoba, 50 Sifton Rd, Winnipeg, MB R3T 2N2, Canada.

e-mail: jim.roth@umanitoba.ca

\section{Sarah T. Saalfeld}

Address: Migratory Bird Management Division, U.S. Fish and Wildlife Service, 1011 East Tudor Road, MS 201, Anchorage, AK 99503, USA.

e-mail: sarah_saalfeld@fws.gov

\section{Gustaf Samelius}

Address: Snow Leopard Trust, 4649 Sunnyside Avenue North, Seattle, USA.

e-mail: gustaf@snowleopard.org

\section{Benoit Sittler}

Address: Chair for Nature Conservation and Landscape Ecology, University of Freiburg, Tennenbacher Str. 4, 79106 Freiburg, Germany.

e-mail: benoit.sittler@nature.uni-freiburg.de

\section{Sergey M. Sleptsov}

Address: Institute of Biological Problems of Cryolithozone, Siberian Branch of the Russian Academy of Sciences, Lenin Avenue, 41, Yakutsk, Sakha Republic, Russia 677980.

e-mail: ornitter@hotmail.com

\section{Paul A. Smith}

Address: National Wildlife Research Centre, 1125 Colonel By Dr, Ottawa, ON K1S 5B6, Canada.

e-mail: Paulallen.smith@canada.ca

\section{Aleksandr A. Sokolov}

Address: Arctic Research Station of Institute of Plant and Animal Ecology, Ural Branch, Russian Academy of Sciences, Zelenaya Gorka Str. 21, Labytnangi, Russia 629400.

Address: Science Center for Arctic Studies, State Organization of Yamal-Nenets Autonomous District, Salekhard, Russia. e-mail: sokhol@yandex.ru

\section{Natalya A. Sokolova}

Address: Arctic Research Station of Institute of Plant and Animal Ecology, Ural Branch, Russian Academy of Sciences, Zelenaya Gorka Str. 21, Labytnangi, Russia 629400.

Address: Science Center for Arctic Studies, State Organization of Yamal-Nenets Autonomous District, Salekhard, Russia.

e-mail: nasokolova@yandex.ru

\section{Mikhail Y. Soloviev}

Address: Department of Vertebrate Zoology, Faculty of Biology, Moscow State University, Moscow, Russia 119991.

e-mail: mikhail-soloviev@yandex.ru

\section{Diana V. Solovyeva}

Address: Laboratory of Ornithology, Institute of Biological Problems of the North, 18 Portovaya Str, Magadan 685000, Russia. e-mail: diana_solovyova@mail.ru 